\title{
Role model: Hugh Herzig
}

\section{Abi Rimmer speaks to Hugh Herzig, a consultant psychiatrist specialising in eating disorders who recently retired from Avon Wiltshire Partnership Mental Health Trust.}

\section{Abi Rimmer}

The BMJ

Throughout his career, Hugh Herzig has valued the access that his work gives him to his patients' thoughts and feelings.

"I sit down with people and within a couple of sentences we're talking about something painful and personal and important in their lives which is really troubling them," he says. "I think that's unusual. It's a privilege that I find enriching and rewarding, and something of an honour."

Herzig is from a family with no medical background who were "more keen on the arts," and he completed his first degree in music at York University.

A year after he graduated, Herzig decided he wanted to become a doctor and while at medical school he discovered psychiatry. "I found that the psychiatrists were interesting people," he says. "They were a very broad church and they sometimes fundamentally disagreed with each other which I found stimulating."

After graduating from United Medical and Dental Schools of Guy's and St Thomas' Hospitals (now King's College London School of Medicine) in 1990, Herzig began his training in south London where his interest in his patients' lives sometimes got him into trouble. "I was a very inefficient house officer," Herzig says. "I would take long histories of all the patients, even people who had come in for a routine operation. I found myself fascinated by personal stories, and somehow couldn't stop myself. I always ran late."

Herzig's early psychiatric training was followed by two years of voluntary work in Malawi, where he found himself the only psychiatrist in a country of 10 million people. On his return to the UK he moved to Bristol and completed his higher psychiatry training in the Severn Deanery.

His person centred clinical approach and enthusiasm for psychotherapy eventually led him to work with people with eating disorders, and in 2003 he became the first consultant in this specialty at the Avon Wiltshire Partnership Mental Health Trust. "I'm orientated towards psychological approaches to treatment," he says. "With eating disorders there's often very little we can do pharmacologically for our patients. We need to be broad and flexible in our clinical approach; these patients really do need holistic care."

In his 15 years as a consultant, Herzig has seen the STEPs Eating Disorder Service expand from a few beds on the end of an acute psychiatric ward and a small community team. "We now have a bigger multidisciplinary community team, a 10 bed ward with our own team of nurses running it, and we're very proud of our unique primary care eating disorder service seeing patients in GP surgeries."

As well as psychiatry trainees, since 2012 Herzig has welcomed doctors in the first year of their foundation training into his unit. Although the highly specialised service may seem an unusual initial placement, Herzig sees the post as beneficial for newly qualified doctors.

"We teach our first year trainees about responding to distressed and anxious patients. Often we just can't take the distress away - there is no quick solution. Doctors must learn to be containing and supportive, rather than reaching for a quick fix such as prescribing a drug," Herzig says.

"Doctors are trained to fix things, but actually there is a lot we can't fix. Only time can help," he adds. "This job exposes young doctors to that in a supportive way and I think it's an important lesson."

During their time in the unit, trainees also learn about patients ambivalence to treatment, Herzig says. "All the patients on my unit wish they were elsewhere. They wish they didn't have to have the treatment and they sometimes resist it intensely," he says. "That's a foreign concept to a newly qualified doctor who might expect patients to gratefully receive their professional wisdom, diagnosis, and treatment. People with eating disorders don't do that. They are very ambivalent about it."

Having now retired from his role as a full time consultant, Herzig plans to return to his first love: music. "I'm a musician and a cellist so I'm going to do lots more music," he says.

"What I don't know is how much I define myself as a doctor-how much of my identity is wrapped up with being Dr Hugh Herzig, the consultant psychiatrist and lead for the eating disorder service," he adds. "As I retire I'm a bit worried about that-but I think I'll cope."

\section{Nominated by Anna Rose-Morris}

What has inspired me the most about Hugh Herzig is his ability to understand the battle that goes on inside a patient's head and then guide them through this towards a place of peace.

$\mathrm{He}$ is also a brilliant teacher and mentor to students, juniors, and colleagues, inspiring medics to pursue a career in psychiatry and value mental health alongside physical health.

Anna Rose-Morris is a psychiatry trainee in the Severn Deanery Nominate a role model: To nominate someone who has been a role model during your medical career, send their name, job title, and the reason for your nomination to arimmer@bmj.com. 
